\title{
Influence of Mixture Proportions on Fresh and Mechanical Properties of Self-consolidating Concrete
}

\author{
Ghafur H. Ahmed* \\ Department of Highway and Bridge Engineering, Technical Engineering College, Erbil Polytechnic University, Erbil, Kurdistan Region, Iraq
}

\author{
${ }^{*}$ Corresponding author: \\ Ghafur H. Ahmed, \\ Department of Highway \\ and Bridge Engineering, \\ Technical Engineering \\ College, Erbil Polytechnic \\ University, Erbil, Kurdistan \\ Region, Iraq. E-mail: ghafur. \\ ahmed@epu.edu.iq
}

Received: 03 February 2021 Accepted: 26 May 2021

Published: 30 December 2021

\section{DOI}

10.25156/pti.v11n2y2021.pp17-25

\section{A B S T R A C T}

Self-consolidating concrete (SCC) is a concrete that able to flow and consolidate under its own weight, and it is cohesive enough to fill spaces of almost any size and shape without segregation or bleeding. In this study, workability and strength characteristics of seven SCC mixes were examined and compared with two additional vibrated mixes of normal and high strength. For this purpose, the flowability, deformability, and passing ability of fresh concrete mixes were tested through slump test, slump flow, T500, and the J-ring tests. Furthermore, the hardened concrete specimens were tested for mechanical properties with the variation in shape and size of the specimens at six different ages. The results revealed that addition of micro-silica is more effective in improving concrete workability and strength than blended micro-silica and fly ash. A well-designed SCC could have an excellent flow $(730 \mathrm{~mm})$ and passing ability $(\Delta \mathrm{H}=4 \mathrm{~mm})$, without sacrificing the early strength (22.3 $\mathrm{MPa}$ in 1 day), or long-term strength (107.7 MPa in 90 days). Results also showed that the compressive strength and the tensile strength of SCC mixes were less affected by specimen shape and size compared to conventional concrete mixes.

Keywords: Self-compacting concrete; Mechanical properties; Fresh concrete; Mix proportions; Slump flow

\section{INTRODUCTION}

The development of self-compacting concrete is considered as a significant achievement in concrete technology because of several positive features. Self-consolidating concrete (SCC) is an innovative material with an excellent rheological behavior that does not require vibration for placing and compaction. It is able to flow and spread under its own weight, completely filling formworks even in the presence of congested reinforcement cages (Piekarczyk, 2013; Hamzah et al., 2015; Pineaud et al., 2016). Based on these properties, SCC may contribute to a significant improvement of the quality of concrete structures and opens up new fields for the application of concrete. The designation selfconsolidating is based on the fresh concrete properties of the material, and therefore, the degree of compactability, the deformability, and the viscosity in connection with different mix compositions were investigated frequently. However, it is also to verify, to what extent the modifications of the mixture composition of SCC affect the hardened concrete mechanical properties (Holschemaeher et al., 2003; Noumowe et al., 2006; Afroughsabet et al., 2017).

The design procedure of SCC mixtures is determined by an increased cement content; new generation superplasticizers; and an additive of a reactive material in the form of silica fume or fly ash. A combination of a viscosity-enhancing admixture and water reducers in SCC enhances the viscosity of a fluid mixture and ensures higher resistance to bleeding, segregation, and surface settlement (Aslani and Samali, 2015; Dybel et al., 2018). Inclusion of supplementary cementitious materials (SCMs) in SCC is increasing day by day due to their flowability and structural performance, environmental friendliness, and energy conservation implications. Worldwide, there is a wide range of mixture proportions that can produce a SCC successfully. However, in most of these compositions, a number of key factors fall within limiting values. Due to the relatively short history of SCC, there is a lack of information about its long-term performance in real structures, its practical applications were still limited. This is due to the fact that its properties are not fully known, while its performance is highly sensitive to small changes in the mix parameters. Systematic investigations with respect to the influence of individual components of the concrete mix, as well as alternative different mix proportions, have rarely been carried out. The two major obstacles that prevent a wider implementation of SCC in today's construction are (i) its high materials cost $(25-50 \%$ higher than conventional concrete) due to the expensive chemical admixtures and the large content 
of fine materials and (ii) the lack of knowledge of the properties of SCC incorporating a low volume of SCM and its performance (Boel et al., 2008; Kumar et al., 2016). In the view of this understanding, the research is designed to present an analysis of the compendious materials used in self-compacting concrete to understand how these materials wield influence on the overall performance of the concrete. Many authors have used a medium to high volumes of SCM, while this study is intending to use the lowest possible volume of SCM, which can guarantee an acceptable flow of concrete, at the same time, not influencing or decreasing the mechanical properties significantly, especially the early age and the long-term compressive strength. Influence of the superplasticizer dosage, cement to the aggregate ratio, and water to the binders' ratio, on the fresh and mechanical properties of SCC; and, influence of concrete age, shape and size of the specimens, are additional parameters that have been investigated in this study.

\section{MATERIALS AND METHODS}

\section{Materials}

Source and quality of materials used in mixture preparation have a great role in overall concrete properties, and mineral admixtures are the key part of modern concrete technology. In this work, the following materials were used for concrete mixtures: (1) Cement: The cement was ordinary Portland cement CEM-I 42.5R, tested for chemical composition and physical properties, and conformed to ASTM C150 (2017) specifications, as shown in Table 1. (2) Silica fume: The type was a ready to use powdered micro-silica concrete admixture, which consists primarily of very fine $\mathrm{SiO}_{2}$ particles $(93 \%)$. The product would react chemically with the calcium hydroxide in the cement paste which yields a calcium silicate hydrate gel that significantly enhances strength and durability as well as self-consolidating properties. (3) Fly ash: The fly ash was powdered cement addition Class-F. It was a high quality and consists primarily of silicate glass containing silica, alumina, iron, and calcium. (4) Mixing water: Ordinary drinking water was used for mixing and curing of all kinds of concrete. It was clean and free from injurious amounts of oil, organic materials, and other deleterious substances. (5) Superplasticizer: High-performance superplasticizer concrete admixture Sika Viscocrete-5930 was used for obtaining workable or flowable concrete with low water to cement ratio. The product is a $3 \mathrm{G}$ superplasticizer and the base of the material is aqueous solution of modified polycarboxylate with a density of $1.095 \mathrm{~kg} / \mathrm{L}$. It meets the requirements for superplasticizers according to ASTM C494 (2019), Types G and F. Through surfaces adsorption and steric separation effect on the cement particles, in parallel to the hydration process, several advantages can be obtained, such as self-compacting behavior; extremely high water reduction; excellent flowability; and increase high early strength development. (6) Fine aggregate: Normal sand was well dried and the sieve analysis was performed according to ASTM C136 (2019). The grading of sand satisfies ASTM C33 (2018) limitations. The average of three random samples was taken, having passing percent shown in Table 2. (7) Coarse aggregate: Fluvial gravel with nominal maximum particle size of $12.5 \mathrm{~mm}$ was used for concrete mixes, after well drying and removing any impurities. The average grading of three samples was according to Grade-7 of ASTM C33, as shown in Table 2.

\section{Mixture Proportions}

Controlling the ratio of the ingredient is the most important factor for obtaining a desired class of concrete. Table 3 is showing the weight proportion of the materials relative to cement weight. The mixes M1 (a normal strength concrete - NSC) and M2 (a high-strength concrete - HSC) were provided as reference mixes for comparison of mechanical properties of SCC with other conventional mixes. The mixes M3 through M9 were various combinations of materials for determining the sensitivity of the mix proportions on the resulted SCC fresh and hardened properties; for instance, changing (increasing or decreasing) the amount of coarse aggregate by $1 \%$ almost has a negligible effect on the mix properties, while changing $1 \%$ of the superplasticizer have a great influence on both fresh and hardened properties of the mixtures; thus, the SCC mixes are more sensitive to any tolerance in superplasticizers than in aggregates ratios. In SCC, the

Table 1: Chemical composition and physical properties of the cement

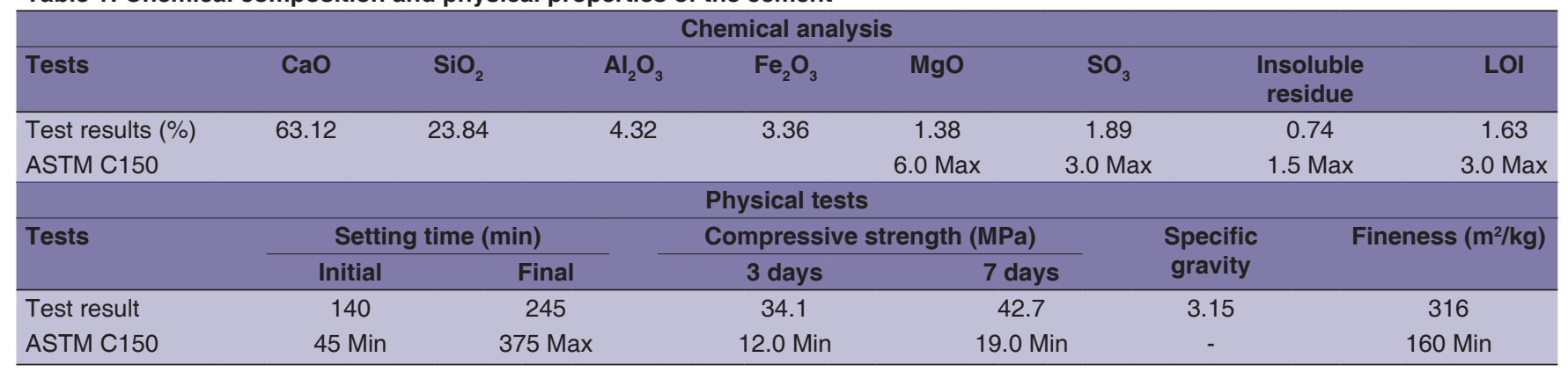


Table 2: Grading of coarse and fine aggregates

\begin{tabular}{lcccccccccccc}
\hline Material/sieve size $(\mathbf{m m})$ & 19 & $\mathbf{1 2 . 5}$ & $\mathbf{9 . 5}$ & $\mathbf{4 . 7 5}$ & $\mathbf{2 . 3 6}$ & $\mathbf{1 . 1 8}$ & $\mathbf{0 . 6 0}$ & $\mathbf{0 . 3 0}$ & $\mathbf{0 . 1 5}$ & $\mathbf{0 . 0 7 5}$ & Fine. M. \\
Coarse aggregates & 100 & 94 & 58 & 1 & 0 & & & & & & & \\
ASTM C33 limits & 100 & $90-100$ & $40-70$ & $0-15$ & $0-5$ & & & & & \\
Fine aggregates & & & 100 & 98 & 84 & 64 & 38 & 16 & 4 & 0 & 3.0 \\
ASTM C33 limits & & & 100 & $95-100$ & $80-100$ & $50-85$ & $25-60$ & $5-30$ & $0-10$ & $0-3$ & $2.3-3.1$ \\
\hline
\end{tabular}

Table 3: Mix proportions of the tested concrete classes

\begin{tabular}{|c|c|c|c|c|c|c|c|c|}
\hline \multirow[t]{2}{*}{ Mix \# } & \multirow[t]{2}{*}{ Concrete class } & \multicolumn{7}{|c|}{ Mix composition by weight (relative to cement) } \\
\hline & & Cement & Sand & Gravel & Micro-silica (\%) & Fly ash (\%) & Superplasticizer (\%) & Water/Powder \\
\hline M1 & NSC & 1.0 & 3.0 & 4.0 & & & & 0.60 \\
\hline M2 & HSC & 1.0 & 1.5 & 2.0 & & & 0.5 & 0.33 \\
\hline M3 & SCC1 & 1.0 & 2.0 & 3.0 & 8.0 & & 2.0 & 0.35 \\
\hline M4 & SCC2 & 1.0 & 2.0 & 3.0 & 8.0 & & 2.0 & 0.33 \\
\hline M5 & SCC3 & 1.0 & 2.0 & 3.0 & 8.0 & & 1.5 & 0.31 \\
\hline M6 & SCC4 & 1.0 & 2.0 & 3.0 & 8.0 & & 1.0 & 0.35 \\
\hline M7 & SCC5 & 1.0 & 2.1 & 2.4 & 6.0 & & 1.0 & 0.33 \\
\hline M8 & ScC6 & 1.0 & 2.1 & 2.4 & 2.5 & 3.5 & 1.0 & 0.31 \\
\hline M9 & SCC7 & 1.0 & 2.1 & 2.4 & 2.5 & 3.5 & 1.0 & 0.35 \\
\hline
\end{tabular}

NSC: Normal strength concrete, HSC: High-strength concrete, SCC: Self-consolidating concrete

paste is the vehicle to transport the aggregate; therefore, the volume of the paste must be greater than the void volume in the aggregate so that all individual aggregate particles are fully coated and lubricated by a layer of paste. This increases fluidity and reduces aggregate friction, it reduces aggregate interlock and bridging when the concrete passes through narrow openings or gaps between reinforcement, and increases the passing ability. Compared to traditional vibrated concrete, the basic mix design proportions of SCC are as follows: It normally contains lower coarse aggregate, increased paste content, and low water/powder (w/p) ratio, with the addition of superplasticizers.

\section{Tested Concrete Properties}

\section{Fresh concrete properties}

Several different test methods have been developed to characterize the fresh properties of SCC through measuring of the filling ability, passing ability, and resistance to segregation. The rheology of fresh SCC is primarily described by its yield point and plastic viscosity. The yield point defines the force required to make the concrete flow. The speed of flow of SCC is associated to its plastic viscosity which describes the resistance of SCC to flow under external stress. SCC should have a relatively low yield value to ensure high-flow ability, a moderate viscosity to resist segregation and bleeding (Aggarwal et al., 2008). The workability tests carried out in this study were slump test, slump flow test, and J-Ring test. Slump test is generally acceptable as a measure of workability for concrete mixes having 15-230 $\mathrm{mm}$ slump, the test was used to determine the workability of non-flowable concretes and having a settlement when the cone is raised; while, if the concrete is non-plastic or it is not adequately cohesive, slump test is no more reasonable. The slump test was performed according to ASTM C143 (2020) for NSC and HSC mixes, as shown in Figure 1. Flow test was performed for SCC types, namely, micro-silica-based concrete, and blended micro-silica-fly ash mixes, according to ASTM C1611 (2018), to assess flowability and flow rate in the absence of obstructions. The fresh concrete was poured into a cone as used in slump test. When the cone was withdrawn upwards, the time from commencing upward movement of the cone to when the concrete has flowed to a diameter of $500 \mathrm{~mm}$ is measured as T500. The two diameter of the dispersed concrete at right angles were measured, and the average was recorded as slump flow. The restricted flow test (J-Ring) was also performed according to ASTM C1621 (2017), for SCC classes, the test is quite interesting for regions with dense reinforcement cages. The ring represents reinforcement inside the molds, which is normally restricts spreading of the concrete.

\section{Hardened concrete mechanical properties}

The most common tests for the evaluation of different concrete classes are the strength tests. Mechanical properties of concrete (such as tensile strength and elastic modulus) are related to compressive strength by international standards or RC design codes. The relations can predict quite accurate results for conventional concretes, whereas the formulas could be insufficiently accurate where applied to SCC. Hence, it is necessary to determine new relations for non-ordinary concrete classes, such as SCC. In this study, the compressive strength of concrete was obtained by testing different size and shapes of specimens [Figure 2]: (1) $100 \mathrm{~mm}$ and $75 \mathrm{~mm}$ cubes, according to BS EN 123901 (2012), (2) $\emptyset 100 \times 200 \mathrm{~mm}$ and $\emptyset 150 \times 300 \mathrm{~mm}$ cylinders, according to ASTM C39 (2020), and (3) portion of prisms $(75 \times 75 \times 135-202 \mathrm{~mm})$ broken in flexure, according to 
ASTM C349 (2018). Age of concrete specimens was also considered for evaluation of the gained strength at each stage. The compressive strength tests were performed at $1,3,7,28,56$, and 90 days.

To determine the tensile behavior of the concrete mixes, splitting tensile strength for $\emptyset 100 \times 200 \mathrm{~mm}$ cylinders was performed according to ASTM C496 (2017), in which, three cylinders were tested for each mix. Another commonly used test for evaluating concrete tensile properties is modulus of rupture, for this test, three prims of $75 \times 75 \times 350 \mathrm{~mm}$ were prepared for each of the mixes and tested with $300 \mathrm{~mm}$ clear span for third point loading (four-point load test), according to ASTM C78 (2018). Three additional groups of specimens with different dimensions were also tested for flexural strength, in which the depth of the concrete was $50 \mathrm{~mm}$, while supported length and the width of the specimens were variable, and two specimens were taken for each size, as shown in Figure 3. As a result, four types of prisms were tested for flexure (depth $\times$ width $\times$ length - clear span): Cast prisms $75 \times 75 \times 350-300 \mathrm{~mm}$ and $50 \times 200 \times 400-300 \mathrm{~mm}$ and saw-cut prisms $50 \times$ $100 \times 300-240 \mathrm{~mm}$ and $50 \times 100 \times 400-300 \mathrm{~mm}$.
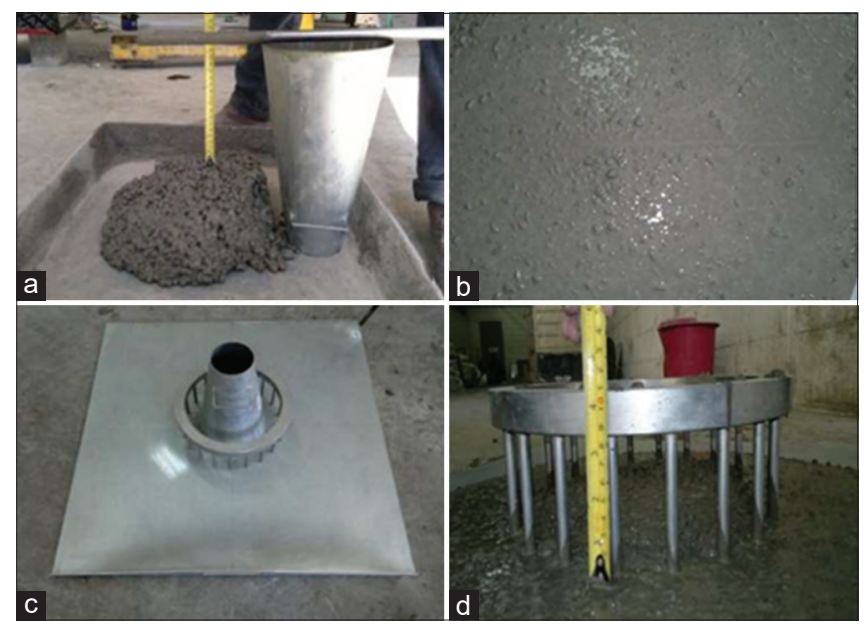

Figure 1: (a) Slump test for non-flowable mixes, (b) a selfconsolidating concrete without segregation (c and d) restricted slump flow test (J-ring)

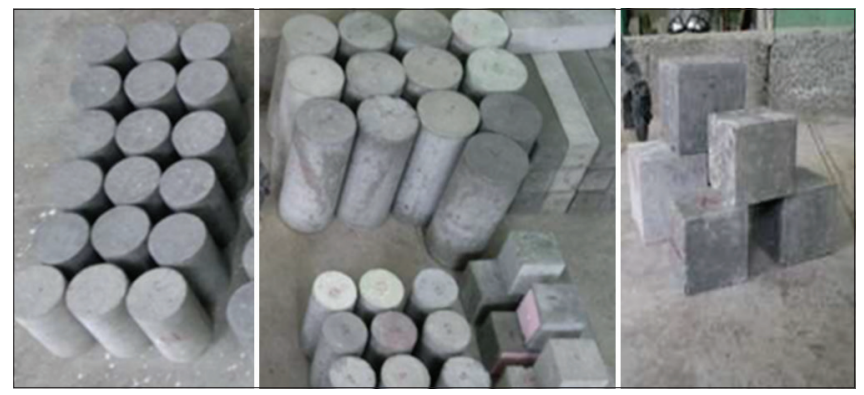

Figure 2: Specimens with different size and shape for compressive strength test

\section{RESULTS AND DISCUSSION}

\section{Fresh Concrete Test Results}

The standard slump test results were $180 \mathrm{~mm}$ and $130 \mathrm{~mm}$ for M1 and M2 mixes, respectively. Although the HSC (M2) was containing a higher cement content and a ratio of $0.5 \%$ of superplasticizer, while the settlement value was less, which is basically referred to the lower $\mathrm{w} / \mathrm{c}$ ratio. The slump flow test was used to evaluate the free deformability (T500) and flowability (flow diameter). Slump flow values shown in Table 4 and Figure 4 are representing the mean diameter (measured in two perpendicular directions) of concrete after lifting the standard slump cone. It is obvious that the M3 to M6 mixes not accepted as self-consolidated concrete, while the mixes M7-M9 could met the acceptance criteria of EFNARC (2005). For a concrete mix to flow over a smooth surface, the aggregate proportioning shall be optimized by increasing the ratio of the fine aggregate to the total aggregate to about 45\%. The lower flow diameter for M3-M6 mixes was mostly referred to the mentioned reason, since they almost have a fine/aggregate ratio of 0.4 , while the ratio was 0.47 for other mixes (M7-M9) by which a perfect flow was obtained. When comparing

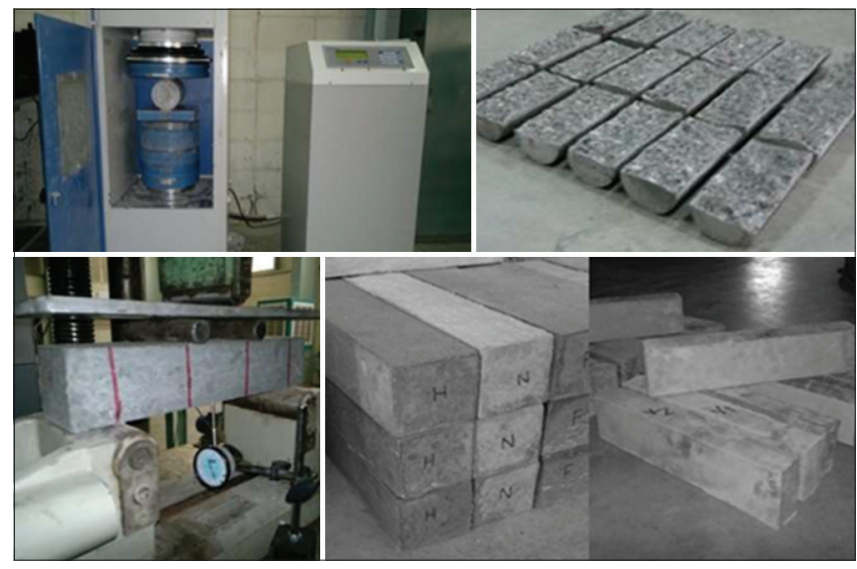

Figure 3: (Top) Cylinders in splitting tensile strength test, (Bottom) flexural strength test and prepared prisms

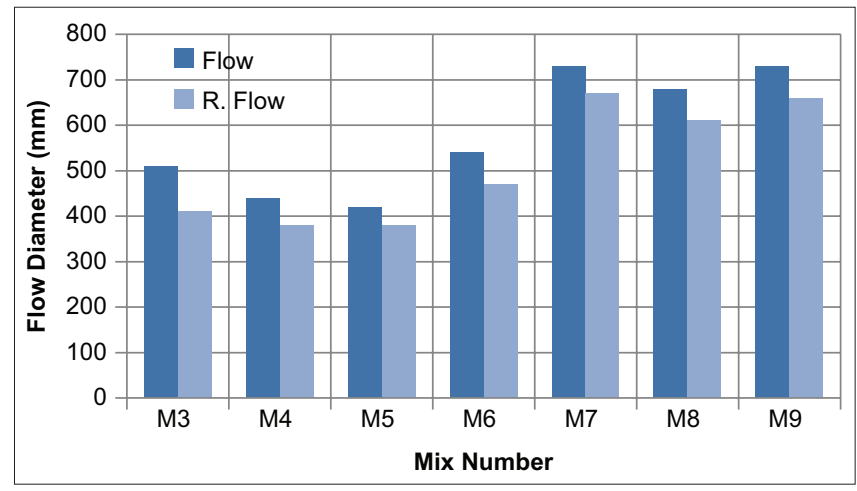

Figure 4: Slump flow and restricted flow diameter for the tested mixtures 
Table 4: Flow test result of silica fume and fly ash-based concrete mixes

\begin{tabular}{|c|c|c|c|c|c|c|c|}
\hline \multirow[t]{2}{*}{ Mix\# } & \multirow{2}{*}{$\begin{array}{l}\text { Concrete } \\
\text { class }\end{array}$} & \multicolumn{2}{|c|}{ Flow (flowing ability) } & \multicolumn{3}{|c|}{ Restricted flow (passing ability) } & \multirow{2}{*}{$\begin{array}{c}\text { Meeting } \\
\text { acceptance criteria } \\
\text { (EFNARC 2005) }\end{array}$} \\
\hline & & Flow diameter $(\mathrm{mm})$ & T500 (Sec) & Flow diameter $(\mathrm{mm})$ & T500 (Sec) & $\Delta \mathbf{H}(\mathrm{mm})$ & \\
\hline M3 & SCC1 & 510 & 3.6 & 410 & 3.9 & 6 & No \\
\hline M4 & SCC2 & 440 & 4.1 & 380 & 4.3 & 6 & No \\
\hline M5 & SCC3 & 420 & 3.8 & 380 & 4.0 & 6 & No \\
\hline M6 & SCC4 & 540 & 3.5 & 470 & 4.1 & 5 & No \\
\hline M7 & SCC5 & 730 & 2.8 & 670 & 3.6 & 4 & Yes \\
\hline M8 & SCC6 & 680 & 3.1 & 610 & 4.0 & 4 & Yes \\
\hline M9 & ScC7 & 730 & 3.5 & 660 & 3.8 & 3 & Yes \\
\hline \multicolumn{2}{|c|}{ Acceptance criteria } & $550-850$ & $2-5$ & & & $0-10$ & \\
\hline
\end{tabular}

SCC: Self-consolidating concrete

M7 (6\% micro silica) with M9 (blended 2.5\% micro silica $+3.5 \%$ fly ash), the first exhibited a better flow, in spite of the higher w/p ratio of the second by $2 \%$. This was compatibility of the two measured parameters, and it is proofing that silica fume was producing better flowability on a horizontal surface in addition to its higher compressive strength, since the fly ash particles were relatively larger compared to micro particles of silica. The results of the restricted flow tests are shown in Table 4, noting that the J-Ring can decrease the flow diameter and T500, while the rate of restriction in silica fume-based concrete was less than that in fly ash concretes. Restriction of concrete flow was causing reduction in flow diameter by $8.2 \%, 8.6 \%$, and $9.6 \%$, respectively, for $\mathrm{M} 7, \mathrm{M} 8$, and $\mathrm{M} 9$ mixes.

\section{Test Results of Mechanical Properties}

Effect of age and the specimen size and shape on compressive strength

The compressive strength of $100 \mathrm{~mm}$ concrete cubes at sic different ages is presented in Table 5 and Figure 5. The rate of gaining strength is different between concrete types; the ratio of gaining strength at 1 day compared to 90 days was $10 \%, 35 \%, 21 \%$, and $10 \%$, respectively, for NSC, HSC, SCC5, and SCC7. This ratio reasonably refers to the low cement content and thereby lower hydration for NSC, higher cement content for HSC, and for the same w/p ratio SCC5 gains less strength due to the slower pozzolanic reactivity of the silica fume than cement. In case of SCC7, the chemical reaction of fly ash was even slower, which causes of gaining less strength when compared to SCC5. In 28 days, NSC gained $59 \%$ of its 90 days strength, and the ratio was $75 \%, 75 \%$, and $85 \%$, respectively, for HSC, SCC 5 , and SCC7. Since the compressive strength depends on the mechanical properties of the hardened cement paste and the adhesion within the ITZ, it is of great interest whether the differences in the concrete composition and the positive changes in the microstructure affect the short- and longterm load-bearing behavior.

It is widely expected for smaller sizes of the cubes $(75 \mathrm{~mm})$ to have compressive strength more than $100 \mathrm{~mm}$
Table 5: Compressive strength of $100 \mathrm{~mm}$ cubes from eight different ages

\begin{tabular}{llcccccc} 
Mix\# & Concrete class & \multicolumn{6}{c}{ Compressive strength (MPa) at (t) } \\
& & $\mathbf{1}$ & $\mathbf{3}$ & $\mathbf{7}$ & $\mathbf{2 8}$ & $\mathbf{5 6}$ & $\mathbf{9 0}$ \\
\cline { 3 - 8 } & & 5.1 & 12.4 & 17.7 & 30.2 & 46.9 & 50.9 \\
M1 & NSC & 29.2 & 44.5 & 53.6 & 62.7 & 76.9 & 83.9 \\
M2 & HSC & 12.7 & 32.1 & 52.4 & 68.7 & 89.2 & 95.2 \\
M3 & SCC1 & 14.1 & 44.8 & 55.2 & 77.5 & 89.0 & 95.6 \\
M4 & SCC2 & 25.7 & 44.9 & 54.8 & 71.0 & 89.3 & 93.2 \\
M5 & SCC3 & 11.8 & 37.9 & 56.2 & 73.6 & 91.5 & 99.5 \\
M6 & SCC4 & 22.3 & 40.4 & 63.7 & 81.2 & 95.4 & 107.7 \\
M7 & SCC5 & 9.6 & 28.9 & 53.6 & 77.3 & 88.4 & 99.1 \\
M8 & SCC6 & 8.6 & 23.2 & 48.4 & 71.0 & 78.9 & 84.0 \\
M9 & SCC7 & &
\end{tabular}

NSC: Normal strength concrete, HSC: High-strength concrete, SCC: Self-consolidating concrete

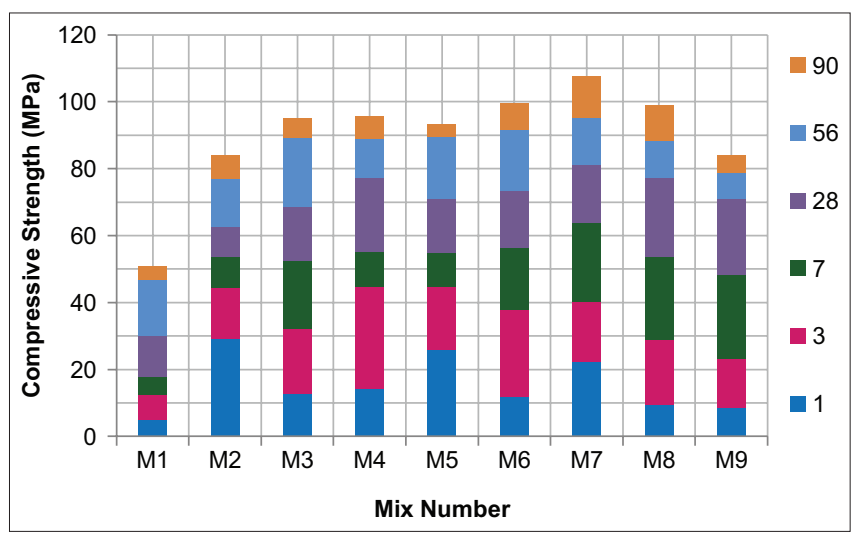

Figure 5: Compressive strength of $100 \mathrm{~mm}$ tested cubes, with the amount of gained strength at different ages

cubes. While the rate of the deviation is not constant, it depends on the concrete types and composition of the microstructure. SCC mixes were less affected by changes in the size of the specimens, Table 6 . The mixture workability was the main reason for higher response against changing in the size of specimens as NSC and HSC mixes were increased in compressive strength by about $6.3-9.4 \%$, but SCC mixes were changed by $5.4-5.7 \%$. A portion of prisms broken in flexure test is also permitted to be tested for compressive strength. While it should be known 
that these portions are always having an aspect ratio less than that of standard specimens, since the length of the specimens might be twice of their height, therefore higher results should be expected. The values of this type of specimens are not randomly affected, but it is the function of the surface area to the height and the original concrete compressive strength.

Evaluation of compressive strength of concrete commonly depends on testing of cylinders, for this purpose, three cylinders were averaged for determining the strength of the mixes. Higher compressive strength values were less affected by specimen shape (Aziz and Ahmed, 2012), since the cube to cylinder factor for NSC mix was 0.81 but it was $0.87,0.91$, and 0.89 for HSC, SCC5, and SCC7 mixes, respectively. Combined effects of aspect ratio and casting direction during test were two factors controlling $\left(\mathrm{f}_{\mathrm{cy}} / \mathrm{f}_{\mathrm{cu}}\right)$ ratio. The $\varnothing 150 \times 300 \mathrm{~mm}$ cylinders are commonly used in North American for practical works and projects, whereas for this research, the maximum aggregate size is not likely coarse to be 37.5 or even $25 \mathrm{~mm}$, which is the main reason for using of larger cylinders. In this study, the nominal maximum aggregate was just $12.5 \mathrm{~mm}$, therefore, it is acceptable to use $100 \mathrm{~mm}$ cubes or cylinders, remembering that always the size effect of the tested specimens cannot be neglected or disregarded, as illustrated in Table 6. When comparing compressive strength of $150 \mathrm{~mm}$ cylinders with $100 \mathrm{~mm}$ cylinders, the ratio of (fcy $150 /$ fcy 100 ) was 0.83 for NSC and increased to 0.90 for SCC 5 mix, which is again proofing that high-strength SCC is less affected by specimen size. By comparing (fcy 150/fcu 100) ratio, the NSC mix had a lowest value of only 0.67 , but the ratio was raised to 0.82 for SCC $5 \mathrm{mix}$. Another important factor that must be remembered herein is the surface planeness of the cylinders that grinded mechanically, but perfect smoothness was not obtained. Ahmed et al. (2021) got the factor 0.794 for NSC, factors of $0.86-0.90$ for SCC, when converting $100 \mathrm{~mm}$ cubes to $\varnothing 100 \mathrm{~mm}$ cylinders. Holschemaeher et al. (2003) obtained the factors of $0.80-0.85$ for vibrated concrete and $0.90-1.00$ for SCC when converting of $150 \mathrm{~mm}$ cubes to $\varnothing 150 \mathrm{~mm}$ cylinders.

\section{Effect of age and the specimen size and shape on tensile strength}

Splitting tensile strength test was performed for $\varnothing 100 \times$ $200 \mathrm{~mm}$ cylinders. For each mix, three cylinders were tested, and results are shown in Table 7. Tensile strength of SCC5 and SCC7 mixes was 1.63 and 1.41 times higher than that of NSC. When comparing the ratio of tensile strength divided by the square root of compressive strength, NSC mix had a value of 0.60 , but higher values were recorded for SCC mixes as 0.63-0.64. Ahmad et al. (2017) recorded 0.61 for a NSC and 0.65 for a SCC. The effects of the specimen size and the age were also considered, for this purpose, cylinders were tested for splitting tensile strength at age of 180 days also, and the average of the three cylinders is shown in Table 7. In the table, it can be noted that the tensile strength at 180 days was increased in a rate of about $4-6 \%$, compared to 90 days' tensile strength. To consider size effect on splitting tensile strength, two Ø150 $\times 300 \mathrm{~mm}$ cylinders were tested, and the results showed less decrease in the strength, compared with compressive strength considering size effects. The loading plane and the failure mechanism might decrease the effect of the size in the tensile strength, and all parameters which influence the characteristics of the microstructure of the cement matrix are of decisive importance in regard to the tensile load-bearing behavior. By evaluating the data in Table 7 , the tendency of higher tensile strengths of SCCs becomes obvious. Presumable the reason for this fact is given by the better microstructure, especially due to the lower and more evenly distributed porosity within the interfacial transition zone - ITZ, which is caused by the higher content of ultrafine particles. Further on the denser, cement matrix of SCC enables a better load transfer. Another method for evaluating concrete tensile properties is flexural strength test, which results are shown in Table 8 . The ratio of $\left(\mathrm{f}_{\mathrm{r}} / \sqrt{\mathrm{f}}_{\mathrm{cy}}\right)$ is commonly taken as 0.63 , but in this study, the value is no more valid for higher strength concrete which was raised to 0.68 for HSC and for SCC that the values were $0.67-0.72$. Ahmad et al. (2017) recorded 0.71 for NSC, 0.69 and 0.72 for SCC mixes. Additional specimens with different geometries were also tested for modulus of rupture of the four main concrete mixes and their results are also shown in Table 8. From analyzing of the data in the table, it can be noted that when decreasing the span of the prism, the flexural strength will be higher. When having wider and thinner beams, the probability of failure at alternative weak paths is increased.

\section{Influence of Ingredients on Strength and Flowability of SCC}

The association of high-strength and self-consolidating properties is a great improvement in producing an improved concrete class. High fluidity is due to the superplasticizer used, while the amount of fine particles smaller than $100 \mu \mathrm{m}$ is an important parameter in improving fluidity and segregation resistance. Water/binder ratio, maximum aggregate size, and the ratio of fine/coarse aggregates are other important parameters for a high-strength concrete with self-compacting properties.

In HSC, careful attention must be given to aggregate size, shape, surface texture, mineralogy, and cleanness. For each source of aggregate and concrete strength level, there is an optimum size aggregate that will yield the most compressive strength per unit of cement. To find the optimum size, trial batches should be made with 
Table 6: Compressive strength of $75 \mathrm{~mm}$ cubes, portion of $75 \mathrm{~mm}$ prisms broken in flexure, and 100 and $150 \mathrm{~mm}$ cylinders, compared with $100 \mathrm{~mm}$ cubes, in 90 days' age

\begin{tabular}{lccccccccc} 
Mix & $\begin{array}{c}\text { fcu } 100 \\
\text { MPa }\end{array}$ & $\begin{array}{c}\text { fcu } 75 \\
\text { MPa }\end{array}$ & fcu 75/100 & $\begin{array}{c}\text { fcp } \\
\text { MPa }\end{array}$ & fcp/fcu100 & $\begin{array}{c}\text { fcy100 } \\
\text { MPa }\end{array}$ & fcy 100/fcu 100 & $\begin{array}{c}\text { fcy } 150 \\
\text { MPa }\end{array}$ & fcy 150/fcu 100 \\
\hline NSC & 50.9 & 55.7 & 1.094 & 61.3 & 1.204 & 41.0 & 0.806 & 34.0 & 0.668 \\
HSC & 83.9 & 89.2 & 1.063 & 97.2 & 1.159 & 72.6 & 0.865 & 63.2 & 0.753 \\
SCC5 & 107.7 & 113.8 & 1.057 & 120.5 & 1.119 & 97.8 & 0.908 & 88.1 & 0.818 \\
SCC7 & 84.0 & 88.5 & 1.054 & 94.8 & 1.129 & 75.0 & 0.893 & 64.9 & 0.773 \\
\hline
\end{tabular}

NSC: Normal strength concrete, HSC: High-strength concrete, SCC: Self-consolidating concrete

Table 7: Splitting tensile strength for different specimen sizes and at different ages

\begin{tabular}{|c|c|c|c|c|c|c|c|}
\hline Mix & $\begin{array}{c}\text { fcy (90 days) } \\
\mathrm{MPa}\end{array}$ & $\begin{array}{c}\text { ft } \varnothing 100(90 \mathrm{~d}) \\
\mathrm{MPa}\end{array}$ & $\mathrm{fct} / \sqrt{\mathrm{f}}$ 'c & $\begin{array}{c}\text { ft } \varnothing 100(180 \mathrm{~d}) \\
\mathrm{MPa}\end{array}$ & $\begin{array}{c}\mathrm{ft}(180 / 90) \mathrm{d} \\
\mathrm{MPa}\end{array}$ & $\begin{array}{c}\text { ft } \varnothing 150(90 \mathrm{~d}) \\
\mathrm{MPa}\end{array}$ & ft $\varnothing 150 / 100$ \\
\hline NSC & 41.0 & 3.90 & 0.601 & 4.14 & 1.061 & 3.56 & 0.913 \\
\hline HSC & 72.6 & 5.24 & 0.615 & 5.44 & 1.038 & 4.96 & 0.947 \\
\hline SCC5 & 97.8 & 6.35 & 0.642 & 6.63 & 1.044 & 6.12 & 0.964 \\
\hline SCC7 & 75.0 & 5.48 & 0.633 & 5.73 & 1.045 & 5.21 & 0.951 \\
\hline
\end{tabular}

NSC: Normal strength concrete, HSC: High-strength concrete, SCC: Self-consolidating concrete

Table 8: Flexural strength (MPa) of concrete specimens (height $\times$ width $\times$ length, L=clear span)

\begin{tabular}{|c|c|c|c|c|}
\hline Mix & $\begin{array}{l}75 \times 75 \times 350 \\
L=300 \mathrm{~mm}\end{array}$ & $\begin{array}{l}50 \times 100 \times 300 \\
L=240 \mathrm{~mm}\end{array}$ & $\begin{array}{l}50 \times 100 \times 400 \\
L=300 \mathrm{~mm}\end{array}$ & $\begin{array}{l}50 \times 200 \times 400 \\
L=300 \mathrm{~mm}\end{array}$ \\
\hline NSC & 4.18 & 4.91 & 4.76 & 3.82 \\
\hline HSC & 5.83 & 5.89 & 5.70 & 4.48 \\
\hline SCC5 & 7.08 & 7.31 & 6.91 & 5.46 \\
\hline SCC7 & 5.82 & 5.94 & 5.55 & 4.63 \\
\hline
\end{tabular}

NSC: Normal strength concrete, HSC: High-strength concrete, SCC: Self-consolidating concrete

$19 \mathrm{~mm}$ and smaller coarse aggregates and varying cement contents. Many studies have found that $9.5 \mathrm{~mm}$ to $12.5 \mathrm{~mm}$ nominal maximum size aggregates give optimum strength (Kosmatka and Wilson, 2011). In SCC, the strength of the aggregate itself and the bond between the paste and aggregate become important factors. The quantity of coarse aggregate in SCC should be the maximum consistent with required workability. Because of the higher percentage of cementitious material, an increase in the fine aggregate content beyond values recommended in standards for NSC is necessary and allowable. The lower content of the fine aggregate was the main reason for SCC1-SCC4 to not meet the workability requirement of SCC, although they have had a high compressive strength. In addition to the mentioned parameters, the cement content remains the most sensitive and effective element, which decided on the entire fresh and hardened concrete properties. Increasing the cement/aggregate ratio from $1 / 5$ to $1 / 4.5$ (SCC4 to SCC5) was increasing the flow diameter from $540 \mathrm{~mm}$ to $730 \mathrm{~mm}$, and the compressive strength from 12.7 to 22.3 $\mathrm{MPa}$ at 1 day, and from 95.2 to $107.7 \mathrm{MPa}$ at 90 days. Due to the increased content of ultra-fines (cement, powder) at SCC, the grain size distribution and packing density will be improved, and therefore, the bulk of the cement paste is stable, coherent, and flowable and the porosity of the interfacial transition zone - ITZ between aggregate and cement paste is decreased.
SCMs were forming a film around the hydrated cement grains, by adsorption or by the formation of insoluble compounds, thereby preventing or slowing more reactions with water. Later, the film breaks down, and the hydration is continued. However, when the amount of admixtures exceeds a critical limit, the hydration process, including setting and formation of hardened structure, never commences, and the paste, will never set. The physicochemical impact of admixtures results in better penetration of water in the surface of cement particles, as a result, the dissolution/precipitation is much more effective. The compressive strength of concrete containing fly ash decreases with an increase in the replacement ratio, however, the micro-silica tends to increase the compressive strength more effectively. This phenomenon is obvious when comparing the SCC5 and SCC6 that the flow diameter was increased from 680 to $730 \mathrm{~mm}$, and the compressive strength was increased from 99.1 to $107.7 \mathrm{MPa}$ at 90 days.

The superplasticizers or water reducers play a key role as workability controlling agents and subsequently affect strength and durability characteristics of the concrete mixes. Better parameters of concretes with these admixtures can be attributed to the more compact, dense microstructure, being the consequence of reduced water content. However, in many cases, the hampering of hydration process in the presence of admixture happens at early age, due to the phenomena occurring on the surface of hydrating particles in the presence of macromolecular compounds. Superplasticizers improve the workability of concrete, reduce segregation and bleeding in freshly mixed, and placed concrete without increasing the water ratio. Optimization of the superplasticizer dosage was a critical task for balancing both important parameters of SCC that was concrete flow and strength characteristics. The ratio of $0.5 \%$ of the superplasticizer used in this study 
was producing a HSC with $83.9 \mathrm{MPa}$, however, it was not flowable, when the ratio was increased to $1 \%$ for better workability, the strength was increased to $99.5 \mathrm{MPa}$, while further increasing the dosage to $2 \%$ was the reason of decreasing the compressive strength to $95.2 \mathrm{MPa}$.

\section{CONCLUSIONS}

1. Addition of micro-silica $(6 \%)$ is more effective considering both workability and strength than the addition of blended micro-silica $(2.5 \%)$ and fly ash $(3.5 \%)$. For the first mix, the flow diameter and the compressive strength were $7.4 \%$ and $8.7 \%$ higher, respectively.

2. For producing a strong and flowable SCC, the fineto-total aggregate ratio shall not be $<45 \%$, since the volume of fines must be sufficient to carry the gravel particles without segregation.

3. Using trial batches are the only way to determine the optimum amount for adding a superplasticizer to SCC. Deviations from the optimum value could significantly reduce the concrete flowability and the strength parameters. The ratio of $0.5 \%$ of the superplasticizer used in this study was producing a HSC with 83.9 $\mathrm{MPa}$, however, it was not flowable, when the ratio was increased to $1 \%$ for better workability, the strength was increased to $99.5 \mathrm{MPa}$, while further increasing the dosage to $2 \%$ was causing to decrease the compressive strength to $95.2 \mathrm{MPa}$.

4. Concrete is a composite material that derives properties from its multiphase and multi-scale ingredients. Increasing the cement/aggregate ratio from $1 / 5$ to $1 / 4.5$ was increasing the flow diameter from $540 \mathrm{~mm}$ to $730 \mathrm{~mm}$, the compressive strength from 12.7 to 22.3 $\mathrm{MPa}$ at 1 day, and from 95.2 to $107.7 \mathrm{MPa}$ at 90 days.

\section{REFERENCES}

Afroughsabet, V., L. Biolzi and T. Ozbakkaloglu. 2017. Influence of double hooked-end steel fibers and slag on mechanical and durability properties of high performance recycled aggregate concrete. Compos. Struct. 181: 273-284.

Aggarwaz, P., R. Siddique, Y. Aggarwal and S. M. Gupta. 2008. Self-compacting concrete procedure for mix design, Leonardo Electronic J. Pract. Technol. 12: 15-24.

Ahmad, S., A. Umar and A. Masood. 2017. Properties of normal concrete, self-compacting concrete and glass fiber-reinforced self-compacting concrete: An experimental study. Proc. Eng. 173: 807-813.

Ahmed, G. H., H. Ahmed, B. Ali and R. Alyousef. 2021. Assessment of high performance self-consolidating concrete through an experimental and analytical multi-parameter approach. Materials. 14: 985.

Aslani, F. and B. Samali. 2015. Constitutive relationships for selfcompacting concrete at elevated temperatures. Mater. Struct.
48: $337-356$.

ASTM C136/C136M-19. 2019. Standard Test Method for Sieve Analysis of Fine and Coarse Aggregates. ASTM International, United States.

ASTM C143/C143M-20. 2020. Standard Test Method for Slump of Hydraulic-cement Concrete. ASTM International, United States.

ASTM C150/C150M-20. 2020. Standard Specification for Portland Cement. ASTM International, United States.

ASTM C1611/C1611M-18. 2018. Standard Test Method for Slump Flow of Self-consolidating Concrete. ASTM International, United States.

ASTM C1621/C1621M-17. 2017. Standard Test Method for Passing Ability of Self-consolidating Concrete by J-Ring. ASTM International, United States.

ASTM C33/C33M-18. 2018. Standard Specification for Concrete Aggregates. ASTM International.

ASTM C349-18. 2018. Standard Test Method for Compressive Strength of Hydraulic-cement Mortars (Using Portions of Prisms Broken in Flexure). ASTM International, United States.

ASTM C39/C39M-20. 2020. Standard Test Method for Compressive Strength of Cylindrical Concrete Specimens. ASTM International, United States.

ASTM C494/C494M-19. Standard Specification for Chemical Admixtures for Concrete. ASTM International, United States.

ASTM C496/C496M-17. 2017. Standard Test Method for Splitting Tensile Strength of Cylindrical Concrete Specimens. ASTM International, United States.

ASTM C78/C78M-18. 2018. Standard Test Method for Flexural Strength of Concrete (Using Simple Beam with Third-point Loading). ASTM International, United States.

Aziz, O. Q. and G. H. Ahmed. 2012. Mechanical Properties of ultra-high Performance Concrete (UHPC). 12 $2^{\text {th }}$ International Conference on Recent Advances in Concrete Technology and Sustainability Issues, Prague, Czech R., Oct. 31-Nov. 2, 2012, American Concrete Institute, ACl Special Publication (SP 289.24). p1-16.

Boel, V., K. Audenaert and G. D. Schutter. 2008. Gas permeability and capillary porosity of self-compacting concrete. Mater. Struct. 41: 1283-1290.

BS EN 12390-1. 2012. British Standard for Testing Hardened Concrete-Part 1: Shape, Dimensions and other Requirements for Specimens and Molds. BSI, London.

Dybel, P., D. Walach and K. Ostrowski. 2018. The top-bar effect in specimens with a single casting point at one edge in highperformance self-compacting concrete. J. Adv. Concrete Technol. 16: 282-292.

EFNARC. 2005. The European Guidelines for Self-Compacting Concrete Specification, Production and Use. The European Federation of Specialist Construction Chemicals and Concrete Systems.

Hamzah, A. F., M. H. W. Ibrahim, N. Jamaluddin, R. P. Jaya and N. E. Z. Abidin. 2015. Cementitious materials usage in selfcompacting concrete: A review. Adv. Mater. Res. 1113: 153-160.

Holschemaeher, K., Y. Klug and D. Weiße. 2003. Self-compacting Concrete-hardened Material Properties and Structural Behavior, System-based Vision for Strategic and Creative Design. Swets and Zeitlinger, Lisse. p1913-1919.

Kosmatka, S. H. and M. L. Wilson. 2011. Design and Control of Concrete Mixtures: The Guide to Applications, Methods, and Materials, EB001. 15 ${ }^{\text {th }}$ ed. Portland Cement Association, Skokie, Illinois, USA. p375-392. 
Kumar, P., R. Kumar and Y. K. Gupta. 2016. Study on normally vibrated concrete to self-compacting concrete. J. Ceram. Concr. Technol. 1(3): 1-18.

Noumowe, A., H. Carre, A. Daoud and H. Toutanji. 2006. Highstrength self-compacting concrete exposed to fire test. J. Mater. Civ. Eng. 18: 754-758.

Piekarczyk, B. L. 2013. The influence of chemical admixtures on cement hydration and mixture properties of very high performance self-compacting concrete. Constr. Build. Mater. 49: 643-662.

Pineaud, A., P. Pimienta, S. Remond and H. Carre. 2016. Mechanical properties of high performance self-compacting concretes at room and high temperature. Constr. Build. Mater. 112: 747-755. 